\title{
InTerferência e Nível de DaNo Econômico de CAPIM-ARRoz sobre o Arroz em Função do Arranjo de Plantas da Cultura ${ }^{1}$
}

\author{
Interference and Economic Weed Threshold (Ewt) of Barnyardgrass on Rice as a Function of \\ Crop Plant Arrangement
}

\author{
AGOSTINETTO, D. ${ }^{2}$, GALON, L. ${ }^{3}$, SILVA, J.M.B.V. ${ }^{4}$, TIRONI, S.P. ${ }^{4}$ e ANDRES, A. ${ }^{5}$
}

\begin{abstract}
RESUMO - Na cultura do arroz irrigado ocorrem elevadas perdas de produtividade de grãos devido à interferência de plantas daninhas, pois estas também estão adaptadas ao ambiente inundado de cultivo do cereal. Objetivou-se avaliar a interferência e determinar o nivel de dano econômico de populações de capim-arroz em arroz irrigado em função do arranjo de plantas da cultura. Foi realizado um experimento em campo, com cultivo de arroz em sistema convencional. Os tratamentos foram constituídos por três arranjos de plantas de arroz, cultivar BRS Pelota (17 e $32 \mathrm{~cm}$ e semeadura a lanço), e nove populações de capim-arroz em cada método de semeadura. O modelo de regressão não linear da hipérbole retangular estima adequadamente as perdas de produtividade do arroz irrigado na presença de plantas de capim-arroz. A cultura do arroz semeada a lanço apresenta maior habilidade competitiva com o capim-arroz em relação à semeadura em linha nos espaçamentos de 17 e $32 \mathrm{~cm}$. A variável área foliar apresenta melhor ajuste ao modelo da hipérbole retangular, comparativamente às variáveis população de plantas, massa seca da parte aérea e cobertura do solo. A utilização de semeadura a lanço aumenta o nivel de dano econômico, justificando a adoção de medidas de controle do capim-arroz em niveis mais elevados de população. Acréscimo na produtividade de grãos, no preço do arroz e na eficiência do herbicida e redução no custo de controle diminuem os valores do nivel de dano econômico, justificando a adoção de medidas de controle em baixas populações de capim-arroz.
\end{abstract}

Palavras-chave: espaçamento entre linhas, modelos matemáticos, Oryza sativa, Echinochloa spp.

ABSTRACT - High yield losses in irrigated rice occur due to weed interference, as weeds are also adapted to the flooded environment where the crop is cultivated. The objective of this study was to evaluate the degree of interference and determine the economic weed threshold of populations of barnyardgrass in irrigated rice, according to crop arrangement. Thus, an experiment was carried out under field conditions with rice crop, under the conventional system. The treatments consisted of three arrangements of rice plants, one cultivar BRS Pelota (17 and $32 \mathrm{~cm}$, hand sown) and nine populations of the competitor barnyardgrass present in each sowing method. The rectangular hyperbolic nonlinear regression model appropriately estimates rice productivity losses in the presence of barnyardgrass plants. Manually sown rice crop shows greater competitive ability against barnyardgrass in relation to the 17 and $32 \mathrm{~cm}$ spacings. The variable leaf area fits better to the hyperbolic model, compared to the variables plant population, shoot dry weight and soil covering. Sowing the crop by hand increases the economic weed threshold, justifying the adoption of measures to control barnyardgrass at higher population levels. Increased grain yield, rice price, herbicide efficiency and control cost reduction decrease the economic weed threshold values, justifying the adoption of control measures in low populations of barnyardgrass.

Keywords: spacing, mathematical models, Oryza sativa, Echinochloa spp.

Recebido para publicação em 5.5.2010 e na forma revisada em 17.12.2010.

2 Engo-Agro‥, Dr., Prof. Faculdade de Agronomia Eliseu Maciel, Universidade Federal de Pelotas - FAEM/UFPel, Dep. de Fitossanidade (DFs), Caixa Postal 354, 96010-900 Campus Capão do Leão-RS, <dirceu_agostinetto@ufpel.tche.br>, Bolsista em Produtividade do CNPq; ${ }^{3}$ Eng $^{0}-$ Agr $^{0}$., D. Sc., Prof. da Universidade Federal do Pampa - UNIPAMPA, Campus Itaqui-RS, Rua Luiz Joaquim de Sá Britto, s/n, 97650-000-Itaqui-RS, <leandrogalon@unipampa.edu.br>; ${ }^{4}$ Alunos do Curso de Agronomia, FAEM/UFPel, <siumar.tironi@gmail.com>, <mbetemps@yahoo.com.br>; ${ }^{5}$ Pesquisador de Herbologia da Embrapa Clima Temperado, BR 392, km 78, Caixa Postal 403, 96001-970 Pelotas-RS, <andre@cpact.embrapa.br>.

Planta Daninha, Viçosa-MG, v. 28, p. 993-1003, 2010. Número Especial 


\section{INTRODUÇÃO}

Entre os fatores bióticos que limitam o potencial de produtividade do arroz irrigado nos Estados do Rio Grande do Sul (RS) e de Santa Catarina (SC), destaca-se a interferência ocasionada pelas plantas daninhas, principalmente aquelas habituadas a sobreviverem em ambiente inundado, como as espécies pertencentes ao gênero Echinochloa, conhecidas vulgarmente como capim-arroz. Essa planta daninha ocorre em altos niveis de infestação e encontra-se distribuída, infestando praticamente todas as lavouras de arroz irrigado do RS e SC, além de apresentar semelhanças morfofisiológicas com a cultura na fase inicial de desenvolvimento, o que tem dificultado o controle com o uso de herbicidas (Andres et al., 2007; Concenço et al., 2007a,b). Outro aspecto importante do capim-arroz diz respeito ao desenvolvimento da resistência tanto cruzada quanto múltipla a vários herbicidas recomendados para seu controle (Andres et al., 2007; Concenço et al., 2008; Galon et al., 2009; Tironi et al., 2009).

Além dos aspectos já comentados, o capimarroz apresenta elevada capacidade competitiva pelos recursos luz, nutrientes, $\mathrm{CO}_{2}$ e água. Mesmo quando em baixas populações, em alguns casos, medidas de controle que eliminem até $99 \%$ da infestação podem não ser suficientes para evitar perdas de produtividade de grãos de arroz que justifiquem a adoção de controle (Agostinetto et al., 2007; Galon et al., 2007a,b; Pinto et al., 2008). As perdas de produtividade das culturas, em decorrência da competição de plantas daninhas, geralmente aumentam quanto mais semelhantes forem suas características morfofisiológicas (Lamego et al., 2004).

Pesquisas envolvendo a capacidade competitiva de culturas versus plantas daninhas permitem desenvolver estratégias de manejo, já que podem definir características que confiram maior habilidade competitiva às espécies cultivadas em detrimento das infestantes (Rizzardi et al., 2004; Agostinetto et al., 2004; Fleck et al., 2006, 2008; Galon et al., 2007b, 2009). A ocorrência de uma planta de capimarroz $\mathrm{m}^{-2}$ pode ocasionar perdas de produtividade de grãos variável de 5 a 30\%, em função do cultivar semeado e da época de entrada de água na lavoura (Galon et al., 2007a; Agostinetto et al., 2007). Isso pode influenciar no manejo que será adotado com a cultura do arroz irrigado em relação à população de capim-arroz presente na lavoura (Andres et al., 2007; Galon et al., 2007b; Pinto et al., 2008).

O principal método de controle de plantas daninhas em arroz irrigado é o químico, em razão da eficiência, praticidade e economia com mão de obra (Erasmo et al., 2004). Entretanto, na atualidade, com os elevados custos na aplicação de herbicidas e também em virtude de pressões públicas quanto a contaminações ambientais em decorrência do uso desse método de controle, outras práticas de manejo tornaram-se necessárias. Nesse sentido, o método auxiliar no controle químico pode ser o cultural, com a adoção de práticas agrícolas que favoreçam a competitividade do arroz em relação ao capim-arroz (Fleck et al., 2004). Entre esses procedimentos culturais, a população e o espaçamento entre linhas da cultura podem auxiliar no fechamento mais rápido dos espaços entre as plantas de arroz, proporcionando à cultura maior sombreamento do solo e, consequentemente, maior competitividade com as plantas daninhas, em especial pelo recurso luz.

Na cultura do arroz irrigado, o manejo do espaçamento entre linhas é uma prática importante, pois, além de ajudar no controle de plantas daninhas com a sua redução, também pode aumentar a produtividade de grãos. A redução do espaçamento entre linhas de 30 para $12,5 \mathrm{~cm}$ e de 20 para $12,5 \mathrm{~cm}$ aumentou a produtividade de grãos de arroz em 15 e $8 \%$, respectivamente (Rieffel Neto et al., 2000). Já Menezes \& Silva (1998) observaram que a redução do espaçamento entre linhas conferiu ao arroz maior habilidade competitiva quando na presença de arrozvermelho.

Para facilitar o uso de determinadas estratégias e identificar o momento certo de controlar as plantas daninhas em lavouras, podem-se utilizar modelos empíricos para estimar a competição com as culturas, os quais descrevem a resposta da perda de produtividade da cultura em relação a uma ou mais variáveis que caracterizam a infestação das plantas daninhas, sem, contudo, ter-se colhido a cultura de interesse. Por meio da 
equação não linear da hipérbole retangular, pode-se estabelecer relação entre perda de produtividade da cultura e variáveis explicativas, como população, massa da matéria seca, cobertura do solo e área foliar das plantas daninhas (Cousens, 1985). De acordo com esse autor, o modelo da hipérbole contém parâmetros que apresentam significado biológico e agronômico, os quais podem ser usados como índices de competitividade.

Outra ferramenta que auxilia a tomada de decisão sobre quando controlar as plantas daninhas refere-se ao nível de dano econômico (NDE). Esse conceito preconiza que a aplicação de herbicidas ou de outros métodos de controle somente se justifica caso os prejuízos causados pelas plantas daninhas sejam superiores ao custo da medida utilizada (Lindquist et al., 1996; Rizzardi et al., 2003; Agostinetto et al., 2005a,b; Galon et al., 2007b). Quando existem elevadas populações de plantas daninhas competindo com as culturas, a tomada de decisão de controle pelos produtores fica facilitada. No entanto, quando as plantas daninhas aparecem em baixas densidades populacionais, a adoção de medidas para controlá-las torna-se dificil, pois os agricultores precisam quantificar as vantagens econômicas associadas ao custo do controle. Assim, é necessário implementar estratégias de manejo que integrem o conhecimento técnico e a análise econômica, aliado ao conhecimento da relação de competição entre a cultura e as plantas daninhas.

Entre os vários fatores que influenciam na competição entre as plantas daninhas e as culturas citam-se aqueles relacionados com as práticas de manejo, como: uso de cultivares com maior habilidade competitiva; épocas de entrada de água na lavoura; densidade de semeadura; e espaçamento entre linhas, que podem diminuir o grau de competição das plantas daninhas, aumentando o NDE e minimizando a necessidade de adoção de medidas de controle. Quando essas informações estão disponiveis, elas podem ter uma função importante, no sentido de mudar o método de manejo que depende principalmente de herbicidas para um sistema voltado ao conhecimento ecofisiológico (Bauer \& Mortensen, 1992). Assim, existem variações nos níveis de dano econômico ocasionados pela competição do capim-arroz com o arroz irrigado, em função de população de plantas do competidor e do arranjo adotado entre as plantas da cultura.

Objetivou-se com este trabalho avaliar o grau de interferência e determinar o nivel de dano econômico de populações de capim-arroz competindo com o cultivar de arroz irrigado BRS Pelota, em função do arranjo de plantas da cultura.

\section{MATERIAL E MÉTODOS}

O experimento foi conduzido em campo, na área experimental da Embrapa Clima Temperado, Capão do Leão-RS, no ano agrícola 2006/07. O solo da área experimental é classificado como Planossolo Hidromórfico Eutrófico solódico, pertencente à Unidade de Mapeamento Pelotas (Embrapa, 2006). A adubação de manutenção foi realizada conforme análises físico-químicas e seguindo-se as recomendações para a cultura do arroz irrigado (SOSBAI, 2005). O método de cultivo adotado foi o convencional, com aração e gradagem, em delineamento experimental completamente casualizado, sem repetição. Cada unidade experimental (parcela) foi composta por área de $7,65 \mathrm{~m}^{2}(1,53 \times 5,0 \mathrm{~m})$.

Os tratamentos foram constituídos por arranjos de espaçamentos entre linhas (17 e $32 \mathrm{~cm}$ e semeadura a lanço) e nove populações de plantas de capim-arroz $(0,4,6,6,10,30$, 36,308 e 332; 0, 2, 6, 6, 18, 40, 52, 296 e 380; e $0,2,6,8,10,26,36,62$ e 302 plantas $\mathrm{m}^{-2}$ ) para cada espaçamento testado, respectivamente. Em razão de o capim-arroz ser proveniente do banco de sementes do solo, o estabelecimento das populações foi variado, pois fatores como infestação, vigor, umidade, entre outros, impedem que se estabeleça exatamente o mesmo número de plantas por área (unidade experimental). As populações da planta daninha foram estabelecidas a partir do banco de sementes do solo, pela aplicação do herbicida cyhalofop-butyl (270 $\left.\mathrm{g} \mathrm{ha}^{-1}\right)+$ óleo mineral (Iharol ${ }^{\circledR}-1,5 \mathrm{~L} \mathrm{ha}^{-1}$ ), quando a cultura se encontrava nos estádios fenológicos $V_{2}$ a $V_{3}$ e a planta daninha, no estádio de duas a três folhas. A época foi escolhida em razão de ser a mais adequada para a aplicação de herbicidas em pós-emergência. As plantas de capim-arroz foram protegidas com copos ou placas (lâminas) plásticas, para que não sofressem injúrias do 
herbicida. O herbicida cyhalofop-butyl foi escolhido devido ao controle de capim-arroz, à seletividade à cultura e por não persistir no solo e/ou na água (Vencill, 2002).

O cultivar de arroz BRS Pelota foi semeado em 15 de novembro, utilizando-se densidade de semeadura de $100 \mathrm{~kg} \mathrm{ha}^{-1}$, o que proporcionou estabelecimento de população aproximada de 400 plantas $\mathrm{m}^{-2}$. A implantação da cultura foi realizada com semeadora regulada conforme os tratamentos propostos; no tratamento a lanço, foi realizada distribuição superficial das sementes com recobrimento manual.

A emergência da cultura ocorreu nove dias após a semeadura, sendo a irrigação por inundação iniciada aos 17 dias após a emergência (DAE), permanecendo até a pré-colheita do arroz. As demais práticas de manejo utilizadas foram aquelas recomendadas pela pesquisa para a cultura do arroz irrigado (SOSBAI, 2005).

A quantificação de população das plantas (PP) de capim-arroz, massa da matéria seca da parte aérea (MSPA), área foliar (AF) ou cobertura do solo (CS) foi realizada aos 34 DAE da cultura. Para determinação da variável PP, foram realizadas contagens das plantas presentes em duas áreas de $0,25 \mathrm{~m}^{2}(0,5 \times 0,5 \mathrm{~m})$ por parcela. A MSPA das plantas de capim-arroz $\left(\mathrm{g} \mathrm{m}^{-2}\right)$ foi determinada pelas coletas das plantas contidas em área de $0,25 \mathrm{~m}^{2}$ por parcela e secas em estufa de circulação forçada de ar a $65^{\circ} \mathrm{C}$, até atingirem massa constante. A quantificação da AF da planta competidora foi realizada com integrador de área foliar, utilizando as folhas das plantas colhidas para avaliação da MSPA. A CS por plantas de capim-arroz foi avaliada visualmente, de modo individual por dois avaliadores, utilizando-se escala percentual, na qual a nota zero corresponde à ausência de cobertura do solo e a nota 100 representa cobertura total do solo.

A quantificação da produtividade de grãos do arroz foi obtida pela colheita das panículas em área útil de $3,57 \mathrm{~m}^{2}$ de cada unidade experimental, quando o teor de umidade dos grãos atingiu aproximadamente $22 \%$. Após pesagem dos grãos, foi determinada sua umidade e, posteriormente, as massas foram uniformizadas para $13 \%$ de umidade.
Com os dados da produtividade de grãos, foram calculadas as perdas percentuais em relação às parcelas mantidas sem infestação (testemunhas), de acordo com a equação 1 :

$$
\operatorname{Perda}(\%)=\left(\frac{R a-R b}{R a}\right) \times 100
$$

em que: $R a$ e $R b$ : produtividade da cultura sem ou com presença de capim-arroz, respectivamente.

Anteriormente à análise dos dados, os valores de MSPA $\left(\mathrm{g} \mathrm{m}^{-2}\right)$, CS (\%) ou AF $\left(\mathrm{cm}^{2}\right)$ foram multiplicados por 100 , dispensando-se assim o uso do fator de correção no modelo (Fleck, et al., 2004; Agostinetto et al., 2004, 2007; Galon et al., 2007a).

As relações entre perdas percentuais de produtividade do arroz cultivado, em função das variáveis explicativas, foram calculadas separadamente para cada densidade de semeadura, utilizando-se o modelo de regressão não linear derivada da hipérbole retangular, proposta por Cousens em 1985 - equação 2.

$$
\mathrm{Pp}=\frac{(i * X)}{\left(1+\left(\frac{i}{a}\right) * X\right)}
$$

em que: $\mathrm{Pp}=$ perda de produtividade $(\%) ; X=$ população de plantas (PP), massa da matéria seca da parte aérea (MSPA), cobertura do solo (CS) ou área foliar (AF) do capim-arroz; e $i$ e $a=$ perdas de produtividade $(\%)$ por unidade de plantas de capim-arroz quando o valor da variável se aproxima de zero ou quando tende ao infinito, respectivamente.

O ajuste dos dados ao modelo foi realizado pelo procedimento Proc Nlin do programa computacional SAS. Para o procedimento de cálculos, utilizou-se o método de GaussNewton, o qual, por sucessivas interações, estima os valores dos parâmetros nos quais a soma dos quadrados dos desvios das observações, em relação aos ajustados, é mínima.

$O$ valor da estatística $F(p \leq 0,05)$ foi utilizado como critério de ajuste dos dados ao modelo. O critério de aceitação do ajuste dos dados ao modelo baseou-se no maior valor do coeficiente de determinação $\left(R^{2}\right)$ e no menor 
valor do quadrado médio do resíduo (QMR).

No cálculo do nível de dano econômico (NDE) utilizaram-se as estimativas do parâmetro $i$ obtidas a partir da equação 2 (Cousens, 1985) e a equação adaptada de Lindquist \& Kropff (1996) - equação 3 :

$$
\mathrm{NDE}=\frac{(C c)}{\left(R * P *\left(\frac{i}{100}\right) *\left(\frac{H}{100}\right)\right)}
$$

em que: $\mathrm{NDE}=$ nível de dano econômico (plantas $\mathrm{m}^{-2}$ ); $C c=$ custo do controle (herbicida e aplicação tratorizada, em dólares ha $\left.{ }^{-1}\right) ; R=$ produtividade de grãos de arroz $\left(\mathrm{kg} \mathrm{ha}^{-1}\right) ; P=$ preço do arroz (dólares $\mathrm{kg}^{-1}$ de grãos); $i=$ perda (\%) de produtividade do arroz por unidade de planta daninha quando o nível populacional se aproxima de zero; e $H=$ nivel de eficiência do herbicida (\%).

Para as variáveis $C c, R, P$ e $H$ (equação 3) foram estimados três valores. Assim, para o custo de controle $(\mathrm{Cc})$ considerou-se o preço médio de US\$ 58,00 $\mathrm{ha}^{-1}$ (270 $\mathrm{g} \mathrm{ha}^{-1}$ de cyhalofop-butyl + adjuvante), sendo os custos máximo e mínimo alterados em $25 \%$, em relação ao custo médio. A produtividade de grãos de $\operatorname{arroz}(R)$ baseou-se na menor $\left(4.930 \mathrm{~kg} \mathrm{ha}^{-1}\right)$, média $\left(6.019 \mathrm{~kg} \mathrm{ha}^{-1}\right)$ e maior $\left(7.060 \mathrm{~kg} \mathrm{ha}^{-1}\right)$ produtividade obtida no RS nos últimos 10 anos (IRGA, 2009). O preço do arroz $(P)$ foi estimado a partir do menor (US\$ 5,70), médio (US\$ 9,61) e maior (US\$19,58) preço do arroz pago por saca de $50 \mathrm{~kg}$ nos últimos 10 anos (IRGA, 2009). Os valores para a eficiência do herbicida $(H)$ foram estabelecidos na ordem de 80,90 e $100 \%$ de controle, sendo $80 \%$ o controle mínimo considerado eficaz da planta daninha (SOSBAI, 2005). Nas simulações de NDE utilizaram-se os valores intermediários para as variáveis que não estavam sendo objeto de cálculo.

\section{RESULTADOS E DISCUSSÃO}

Os resultados foram significativos para todas as variáveis nos arranjos de plantas testados (Figuras 1 a 4). Os dados dos espaçamentos de semeadura $(17,32 \mathrm{~cm}$ e a lanço) ajustaram-se adequadamente ao modelo da hipérbole retangular, com valores de $\mathrm{R}^{2}$ acima de 0,60 e baixos QMR, o que caracteriza bom ajuste ao modelo.

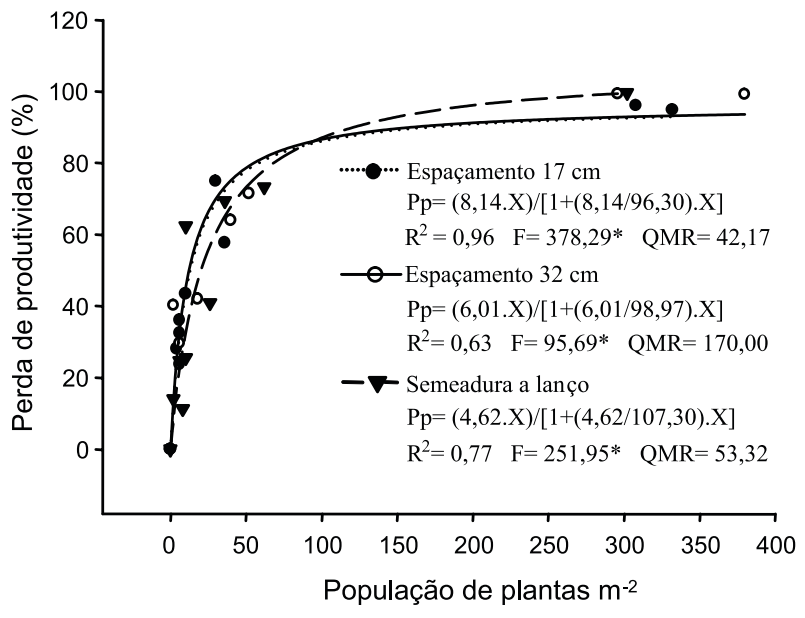

Figura 1 - Perda de produtividade $(\mathrm{Pp})$ de grãos de arroz, cultivar BRS Pelota, em função da população de capim-arroz e de espaçamentos entre linhas, aos 34 dias após a emergência da cultura. Embrapa Clima Temperado, Capão do Leão-RS, 2006/07. ( $\mathrm{R}^{2}$ : coeficiente de determinação; QMR: quadrado médio do resíduo; * Significativo a 5\%).

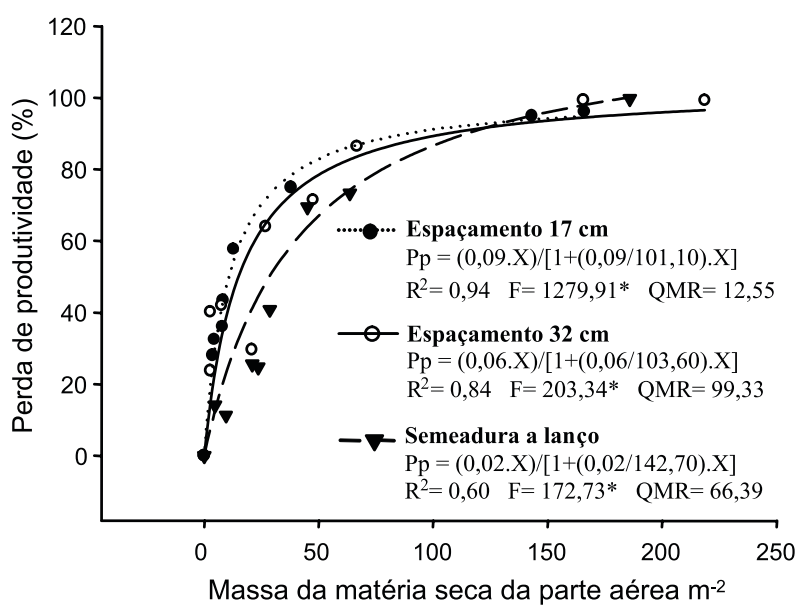

Figura 2 - Perda de produtividade $(\mathrm{Pp})$ de grãos de arroz, cultivar BRS Pelota, em função da massa da matéria seca da parte aérea de capim-arroz e de espaçamentos entre linhas, aos 34 dias após a emergência da cultura. Embrapa Clima Temperado, Capão do Leão-RS, 2006/07. ( $\mathrm{R}^{2}$ : coeficiente de determinação; QMR: quadrado médio do residuo; * Significativo a 5\%).

Observou-se para todas as variáveis que os valores estimados para o parâmetro $i$ tenderam a ser menores quando se efetuou a semeadura a lanço (Figuras 1, 2, 3 e 4). A maior competitividade quando a semeadura foi 


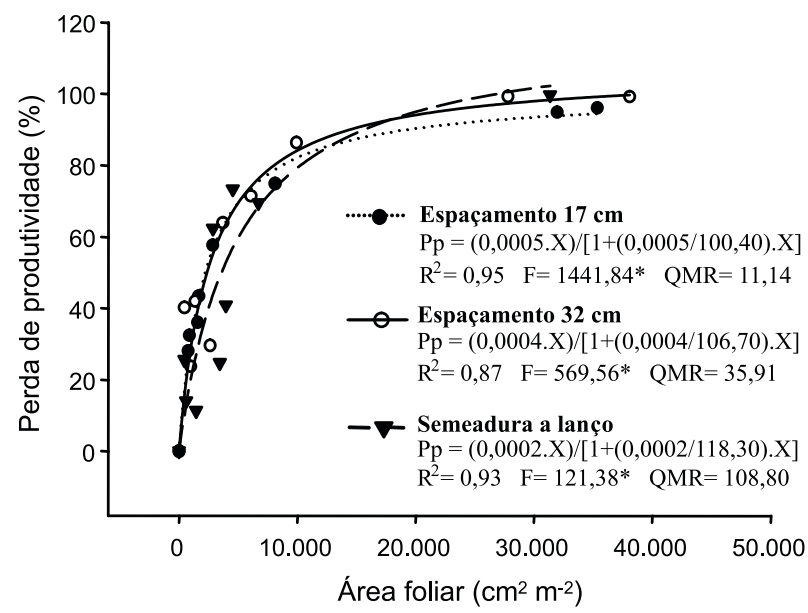

Figura 3 - Perda de produtividade $(\mathrm{Pp})$ de grãos de arroz, cultivar BRS Pelota, em função da área foliar de capim-arroz e de espaçamentos entre linhas aos 34 dias após a emergência da cultura. Embrapa Clima Temperado, Capão do Leão-RS, 2006/07. ( $\mathrm{R}^{2}$ : coeficiente de determinação; QMR: quadrado médio do resíduo; * Significativo a 5\%).

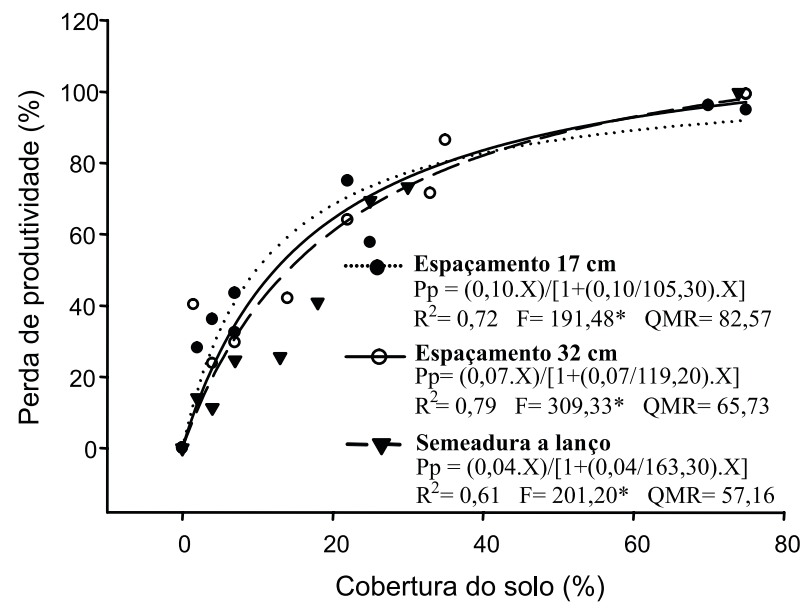

Figura 4 - Perda de produtividade $(\mathrm{Pp})$ de grãos de arroz, cultivar BRS Pelota, em função da cobertura do solo de capim-arroz e de espaçamentos entre linhas, aos 34 dias após a emergência da cultura. Embrapa Clima Temperado, Capão do Leão-RS, 2006/07. ( $\mathrm{R}^{2}$ : coeficiente de determinação; QMR: quadrado médio do resíduo; * Significativo a 5\%).

realizada a lanço pode estar relacionada com a distribuição mais equidistante das plantas na área de cultivo, o que diminui a competição intraespecífica e favorece a competição interespecífica, entre a cultura e as plantas daninhas, com maior aproveitamento dos recursos do meio pelo arroz.
Comparando os dois espaçamentos entre linhas, observou-se que no arranjo de $32 \mathrm{~cm}$ houve incremento na competição do arroz na ordem de 35, 50, 25 e 42\%, para as variáveis $\mathrm{PP}, \mathrm{MSPA}, \mathrm{AF}$ e CS, respectivamente, em comparação ao espaçamento de $17 \mathrm{~cm}$ (Figuras 1, 2, 3 e 4). Resultados similares foram constatados por Pedroso (1987), o qual observou que o cultivar BR-IRGA 409, sob espaçamento entre linhas de $30 \mathrm{~cm}$, produziu $10 \%$ mais grãos que no espaçamento de $10 \mathrm{~cm}$, na média de três anos de cultivo. Por sua vez, Andrade \& Amorim (1995) não constataram diferenças na produtividade de grãos em variedades de arroz cultivadas nos espaçamentos de 20, 30 e $40 \mathrm{~cm}$.

Sendo o parâmetro $i$ um índice usado para comparar a competitividade relativa entre espécies (Swinton et al., 1994), constataram-se valores diferenciados para os arranjos de arroz nas variáveis explicativas testadas (Figuras 1, 2, 3 e 4). A comparação entre os espaçamentos considerando o parâmetro $i$, na média das quatro variáveis explicativas (PP, MSPA, CS ou $\mathrm{AF}$ ), demonstrou que a ordem de colocação em relação à competitividade dos arranjos entre plantas foi: a lanço $>32 \mathrm{~cm}>17 \mathrm{~cm}$. As diferenças observadas entre os resultados dos espaçamentos entre linhas podem ser decorrentes do melhor aproveitamento dos recursos disponiveis no meio, principalmente a luz, e também do erro-padrão na estimativa do parâmetro $i$, podendo ser atribuído à variabilidade associada com experimentação de campo e à plasticidade fenotípica da cultura (Dieleman et al., 1995).

A luz é uma das características mais importantes a se considerar na competição, a qual afeta diretamente a produtividade, dependendo do estádio em que passa a ocorrer o sombreamento, relativamente à definição dos componentes da produtividade (Agostinetto et al., 2004). Ainda segundo esses autores, as folhas sombreadas recebem basicamente luz refletida e de menor intensidade, o que causará diminuição gradativa da taxa fotossintética à medida que se aproxima do solo. Assim, essas variabilidades podem dificultar as estimativas corretas das perdas de produtividade em baixas densidades de plantas de capim-arroz.

Comparando os arranjos de plantas de arroz para a variável $\mathrm{PP}$, com base na perda unitária (i), observaram-se perdas de produtividade de 
$8,1,6,0$ e 4,6\% para os espaçamentos de 17 e $32 \mathrm{~cm}$ e a semeadura a lanço, respectivamente (Figura 1). Vários trabalhos enfatizam a maior habilidade competitiva do arroz com as plantas daninhas com redução do espaçamento entre linhas (Menezes \& Silva, 1998; Rieffel Neto et al., 2000; Agostinetto et al., 2004). Entretanto, neste experimento, em razão de a germinação do capim-arroz ter ocorrido tardiamente, a competição deste no estádio inicial de desenvolvimento da cultura foi reduzida, favorecendo assim a ocorrência de maior afilhamento no espaçamento de $32 \mathrm{~cm}$ entre linhas em relação ao de $17 \mathrm{~cm}$.

As estimativas do parâmetro $a$, independentemente da variável explicativa, foram superestimadas pelo modelo, com perdas de produtividade superiores a $100 \%$ em todos os arranjos de plantas testados, exceto para PP nos espaçamentos de 17 e $32 \mathrm{~cm}$, nos quais se constataram perdas inferiores a $100 \%$ (Figuras 1, 2, 3 e 4). Esses resultados podem ser decorrentes do fato de as maiores populações de plantas de capim-arroz não serem suficientes para estimar adequadamente a perda máxima de produtividade. Segundo Cousens (1991), para obtenção de estimativa confiável para esse parâmetro, há necessidade de incluir no experimento populações muito elevadas de plantas daninhas, acima daquelas comumente encontradas em condições de lavoura. De modo semelhante, Agostinetto et al. (2007) e Galon et al. (2007a), ao estudarem a competição do arroz com o capim-arroz submetido a diferentes métodos de manejo, também constataram perdas superiores a $100 \%$ para o parâmetro $a$.

Uma alternativa para evitar que as perdas de produtividade sejam superestimadas seria limitar a perda máxima em $100 \%$. Contudo, a limitação influenciará a estimativa do parâmetro $i$, podendo resultar em menor previsibilidade no modelo da hipérbole retangular (Streibig et al., 1989).

A comparação entre as variáveis explicativas para todos os arranjos de plantas, em geral, demonstrou melhor ajuste ao modelo para as variáveis $\mathrm{AF}>\mathrm{MSPA}>\mathrm{PP}>\mathrm{CS}$, considerando os maiores valores médios do $\mathrm{R}^{2}$ e os menores valores médios do QMR (Figuras 1, 2, 3 e 4), evidenciando assim que a AF pode ser usada em substituição à variável PP. De modo semelhante, Vitta \& Fernandez Quintanilla (1996) observaram que o modelo que incorporou a variável $\mathrm{AF}$ foi tão preciso quanto o da população de plantas daninhas. Entretanto, vale ressaltar que a $\mathrm{AF}$ apresentou valores estimados extremamente baixos para perdas unitárias de produtividade de grãos. Além disso, a AF não é fácil de ser aferida e sua determinação é demorada, trabalhosa e destrutiva (Vitta \& Fernandez Quintanilla, 1996).

Considerando-se a produtividade média do arroz irrigado no Estado do RS de $6.019 \mathrm{~kg} \mathrm{ha}^{-1}$ (IRGA, 2009), o preço médio de 9,6 dólares $50 \mathrm{~kg}^{-1} \mathrm{e}$ o custo de controle de capim-arroz de 58 dólares ha ${ }^{-1}$, estimou-se que o custo de controle equivale a 5,0\% da produção. Assim, considerando que a presença de uma planta de capim-arroz $\mathrm{m}^{-2}$ ocasionará perdas de produtividade de $8,1,6,0$ e 4,6\%, respectivamente para os arranjos de 17 e $32 \mathrm{~cm}$ e a semeadura a lanço (Figura 1), somente a semeadura efetuada a lanço apresenta perdas de produtividade por interferência abaixo do valor de custo de controle. Esses resultados indicam que o capim-arroz é muito competitivo, mesmo em baixas populações, e que medidas de controle que eliminem até $99 \%$ da infestação podem não ser suficientes para evitar perdas de produtividade que justifiquem a adoção de medidas de controle. Resultados similares foram observados por Agostinetto et al. (2007) e Galon et al. (2007a), ao estudarem a competição exercida pelo capim-arroz ao arroz irrigado em diferentes manejos adotados com a cultura.

Na simulação dos cálculos do NDE (nível de dano econômico) utilizou-se a variável explicativa população de plantas (PP), em razão de ser a mais utilizada em experimentos com esse objetivo (Fleck et al., 2002; Rizzardi et al., 2003; Agostinetto et al., 2005a,b; Galon et al., 2007b).

A comparação da competitividade relativa demonstrou que a semeadura a lanço foi mais competitiva que as demais (Tabela 1). O êxito na implantação de sistema de controle do capim-arroz, na cultura do arroz irrigado, pode decorrer da determinação da população que excede o NDE. Desse modo, constatou-se que os espaçamentos de 17 e $32 \mathrm{~cm}$ apresentaram menores valores de NDE em todas as simulações realizadas, os quais variaram de 0,34 a 
Tabela 1 - Perda de produtividade de grãos de arroz irrigado, cultivar BRS-Pelota, em função da população de capim-arroz e espaçamentos entre linhas, aos 34 dias após a emergência da cultura. Embrapa Clima Temperado, Capão do Leão-RS, 2006/07

\begin{tabular}{|c|c|c|r|r|}
\hline $\begin{array}{c}\text { Espaçamento entre } \\
\text { linhas }\end{array}$ & Perda (\%) de produtividade ${ }^{1 /}$ & $\mathrm{R}^{2}$ & $\mathrm{~F}^{*}$ & $\mathrm{QME}^{2 /}$ \\
\hline $17 \mathrm{~cm}$ & $(8,14 . \mathrm{X}) /(1+(8,14 / 96,30) \cdot \mathrm{X}]$ & 0,96 & 378,29 & 42,17 \\
\hline $32 \mathrm{~cm}$ & $(6,01 . \mathrm{X}) /(1+(6,01 / 98,97) \cdot \mathrm{X}]$ & 0,63 & 95,69 & 170,00 \\
\hline A lanço & $(4,62 . \mathrm{X}) /(1+(4,62 / 107,30) \cdot \mathrm{X}]$ & 0,77 & 251,95 & 53,32 \\
\hline
\end{tabular}

$1 /$ Valor obtido pelo modelo de regressão da hipérbole retangular (Cousens, 1985). * Significativo a 5\% de probabilidade. ${ }^{2} /$ Quadrado médio do erro.

2,03 plantas $\mathrm{m}^{-2}$, comparativamente à semeadura a lanço (Figuras 5, 6, 7 e 8).

O arranjo entre plantas de $17 \mathrm{~cm}$ apresentou valores de NDE de 0,34 a 1,15 plantas $\mathrm{m}^{-2}$ (Figuras 5, 6, 7 e 8). Conforme já relatado anteriormente, isso pode ser em decorrência da competição intraespecífica que ocorreu entre as plantas de arroz em função da menor passagem de luz pelo dossel da cultura e, consequentemente, redução da competitividade do arroz com o capim-arroz. Em comunidades de plantas, a população de determinada espécie no nicho ecológico é um dos fatores mais importantes, pois, quanto maior o adensamento de plantas em certa área, maior será a quantidade de indivíduos que disputaram os mesmos recursos do meio e, desse modo, mais intensa será a competição entre os membros (Christoffoleti \& Victoria Filho, 1996; Maluf, 1999).

Confrontando os três arranjos da cultura e comparando a menor com a maior produtividade de grãos, observou-se diferença no NDE da ordem de 69,6\% (Figura 5). Assim, fica evidente que, quanto mais elevado o potencial de produtividade do arroz, menor será a população de plantas de capim-arroz necessária para superar o $\mathrm{NDE}$, tornando compensatória a adoção de medidas de controle da planta daninha.

Os resultados médios de todos os espaçamentos testados, comparando-se o maior e o menor preço pago pela saca de arroz, demonstraram variação de 3,4 vezes no valor do NDE (Figura 6). Dessa forma, observou-se que, quanto menor o preço pago pela saca de arroz, maior será o número de plantas de capim-arroz necessário para ultrapassar o NDE e compensar o tratamento de controle.

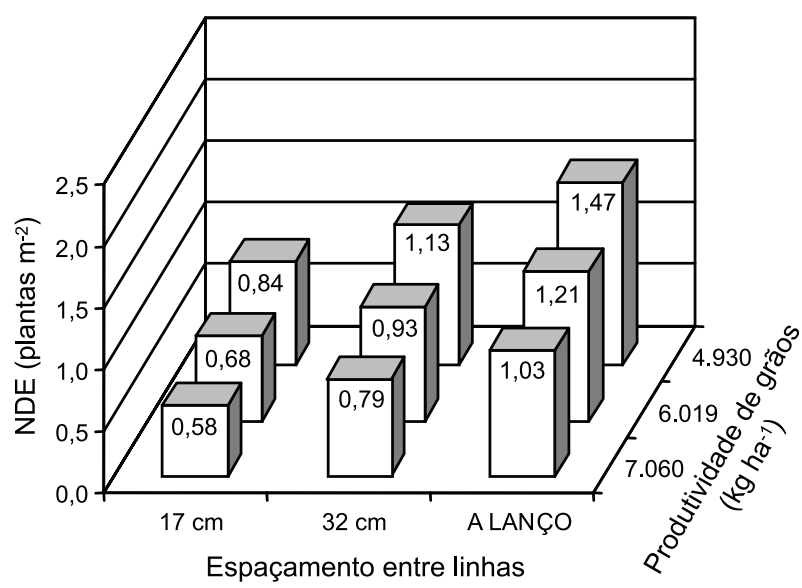

Figura 5 - Nivel de dano econômico (NDE) para arroz irrigado em função da produtividade de grãos, população de capim-arroz e de espaçamentos entre linhas do cultivar BRS Pelota. Embrapa Clima Temperado, Capão do Leão-RS, 2006/07.

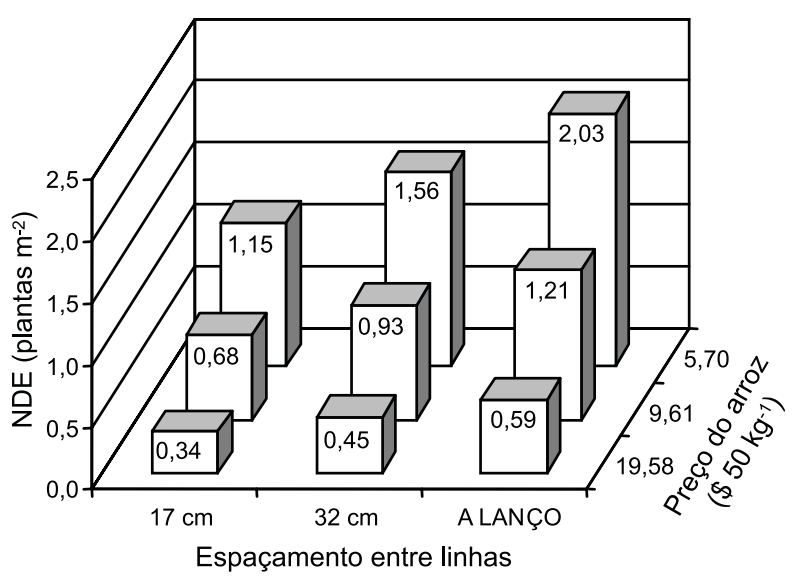

Figura 6 - Nivel de dano econômico (NDE) para arroz irrigado em função do preço do arroz, da população de capim-arroz e de espaçamentos entre linhas do cultivar BRS Pelota. Embrapa Clima Temperado, Capão do Leão-RS, 2006/07. 
Ao comparar a eficiência média do herbicida $(90 \%)$, em relação à menor $(80 \%)$ ou à maior (100\%), observaram-se alterações nos NDE de 11,3 e 10,6\%, respectivamente, nos três arranjos estudados (Figura 7). Desse modo, o nivel de controle influencia o NDE, e, quanto mais elevada for a eficiência do herbicida, menor o NDE.

Ao analisar o custo médio de controle do capim-arroz nos três arranjos de semeadura,

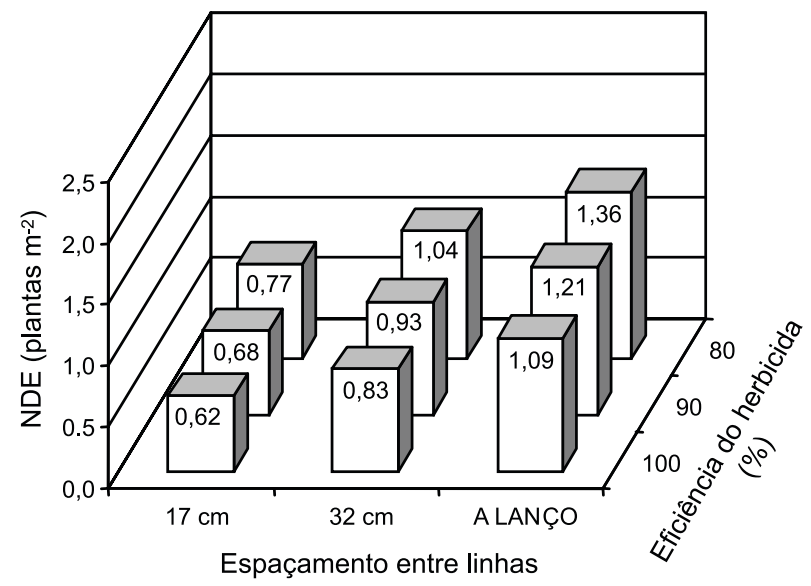

Figura 7 - Nivel de dano econômico (NDE) para arroz irrigado em função de eficiência do herbicida, da população de capim-arroz e de espaçamentos entre linhas do cultivar BRS Pelota. Embrapa Clima Temperado, Capão do Leão-RS, 2006/07.

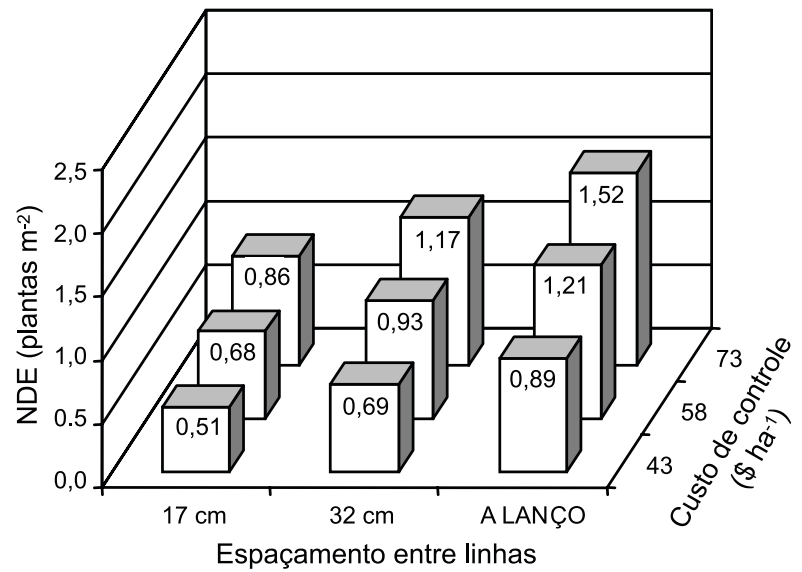

Figura 8 - Nivel de dano econômico (NDE) para arroz irrigado em função de custo de controle, da população de capim-arroz e de espaçamentos entre linhas do cultivar BRS Pelota. Embrapa Clima Temperado, Capão do Leão-RS, 2006/07. verificou-se que o custo mínimo foi $58,9 \%$ inferior ao custo máximo (Figura 8). Assim, quanto mais elevado o custo, maiores são os NDE e mais plantas de capim-arroz $\mathrm{m}^{-2}$ são necessárias para justificar medidas de controle.

Resultado semelhante ao observado neste experimento para as variáveis explicativas do NDE foi encontrado por Galon et al. (2007b) ao estudarem o NDE do capim-arroz sobre o arroz irrigado em função de cultivares e de épocas de entrada de água na lavoura, os quais concluíram que, mesmo quando o capim-arroz se encontra em baixas densidades, há necessidade da adoção de alguma medida de controle, em razão da elevada competitividade dessa planta daninha com o arroz irrigado.

O aumento do potencial de produtividade do arroz, no preço do produto dos grãos colhidos ou na eficiência do herbicida e a queda do custo de controle diminuíram os NDE em todas as simulações efetuadas, para os arranjos de plantas testados. Assim, em lavouras de arroz onde as estimativas do potencial de produtividade são altas, mesmo em menor população de plantas daninhas, justifica-se economicamente a adoção de medidas de controle.

Diante dos resultados obtidos, pode-se concluir que o modelo de regressão não linear da hipérbole retangular estima adequadamente as perdas de produtividade do arroz irrigado na presença de plantas de capim-arroz. A cultura do arroz por semeadura a lanço apresenta maior habilidade competitiva com o capimarroz em relação à das semeaduras nos espaçamentos de 17 e $32 \mathrm{~cm}$. A variável área foliar apresenta melhor ajuste ao modelo da hipérbole retangular comparativamente às variáveis: população de plantas, massa seca da parte aérea e cobertura do solo. A utilização de semeadura da cultura a lanço aumenta o nível de dano econômico, justificando adoção de medidas de controle do capim-arroz em niveis mais elevados de população. Acréscimo na produtividade de grãos, no preço do arroz e na eficiência do herbicida e redução no custo de controle diminuem os valores do nivel de dano econômico, justificando a adoção de medidas de controle em baixas populações de capimarroz. 


\section{AGRADECIMENTOS}

Ao Conselho Nacional de Desenvolvimento Científico e Tecnológico (CNPq-Brasil), à Fundação de Amparo a Pesquisa do Estado do Rio Grande do Sul (FAPERGS) e a Coordenação de Aperfeiçoamento de Pessoal de Nivel Superior (CAPES), pelas concessões de bolsas e pelo apoio financeiro.

\section{LITERATURA CITADA}

AGOSTINETTO, D. et al. Perdas de rendimento de grãos na cultura de arroz irrigado em função da população de plantas e da época relativa de emergência de arroz-vermelho ou de seu genótipo simulador de infestação de arroz-vermelho. Planta Daninha, v. 22, n. 2, p. 175-183, 2004.

AGOSTINETTO, D. et al. Níveis de dano econômico para decisão de controle de genótipo simulador de arroz-vermelho em arroz irrigado. R. Bras. Agroci., v. 11, n. 2, p.175-183, 2005a.

AGOSTINETTO, D. et al. Dano econômico como critério na decisão sobre manejo de genótipos de arroz concorrentes em arroz irrigado. Pesq. Agropec. Bras., v. 40, n. 1, p. 1-9, $2005 b$.

AGOSTINETTO, D. et al. Interferência de capim-arroz (Echinochloa spp.) na cultura do arroz irrigado (Oryza sativa) em função da época de irrigação. Planta Daninha, v. 25, n. 4, p. 689-696, 2007.

ANDRADE, W. E. B.; AMORIM NETO, S. Densidade de semeadura e espaçamentos entre linhas em cultivares de arroz irrigado no Estado do Rio de Janeiro. Lav. Arrozeira, v. 48, n. 420, p. 9-11, 1995.

ANDRES, A. et al. Detecção da resistência de capim-arroz (Echinochloa sp.) ao herbicida quinclorac em regiões orizícolas do sul do Brasil. Planta Daninha, v. 25, n. 1, p. 221-226, 2007.

BAUER, T. A.; MORTENSEN, D. A. A comparison of economic and economic optimum thresholds for two annual weeds in soybeans. Weed Technol., v. 6, n. 1, p. 228-235, 1992.

CHRISTOFFOLETI, P. J.; VICTORIA FILHO, R. Efeitos da densidade e proporção de plantas de milho (Zea mays L.) e caruru (Amaranthus retroflexus L.) em competição.

Planta Daninha, v. 14, n. 1, p. 42-47, 1996.

CONCENÇO, G. et al. Emergência e crescimento inicial de plantas de arroz e capim-arroz em função do nível de umidade do solo. Planta Daninha, v. 25, n. 3, p. 457-463, $2007 \mathrm{a}$.
CONCENÇO, G. et al. Sensibilidade de plantas de arroz ao herbicida bispyribac-sodium em função de doses e locais de aplicação. Planta Daninha, v. 25, n. 3, p. 629-637, 2007 b.

CONCENÇO, G. et al. Método rápido para detecção de resistência de capim-arroz (Echinochloa spp.) ao quinclorac. Planta Daninha, v. 26, n. 2, p. 429-437, 2008.

COUSENS, R. An empirical model relating crop yield to weed and crop density and a statistical comparison with other models. J. Agric. Sci., v. 105, n. 3, p. 513-521, 1985

COUSENS, R. Aspects of the design and interpretation of competition (interference) experiments. Weed Technol., v. 5, n. 3, p. 664-673, 1991.

DIELEMAN, A. et al. Empirical models of pigweed (Amaranthus spp.) interference in soybean (Glycine max). Weed Sci., v. 43, n. 4, p. 612-618, 1995.

EMPRESA BRASILEIRA DE PESQUISA AGROPECUÁRIA - EMBRAPA. Centro Nacional de Pesquisa Agropecuária de Solos. Sistema brasileiro de classificação de solos. Rio de Janeiro: 2006. 412 p.

ERASMO, E. A. L.; PINHEIRO, L. L. A.; COSTA, N. V. Levantamento fitossociológico das comunidades de plantas infestantes em áreas de produção de arroz irrigado cultivado sob diferentes sistemas de manejo. Planta Daninha, v. 22, n. 2, p. 195-201, 2004.

FLECK, N. G.; RIZZARDI, M. A.; AGOSTINETTO, D. Nível de dano econômico como critério para tomada de decisão no controle de guanxuma em soja. Planta Daninha, v. 20, n. 3 , p. $421-429,2002$

FLECK, N. G. et al. Interferência de plantas concorrentes em arroz irrigado modificada por métodos culturais

Planta Daninha, v. 22, n. 1, p. 19-28, 2004

FLECK, N. G. et al. Interferência de Raphanus sativus sobre cultivares de soja durante a fase vegetativa de desenvolvimento da cultura. Planta Daninha, v. 24, n. 3, p. 425-434, 2006.

FLECK, N. G. et al. Competitividade relativa entre cultivares de arroz irrigado e biótipos de arroz-vermelho.

Planta Daninha, v. 26, n. 1, p. 101-111, 2008.

GALON, L. et al. Estimativa das perdas de produtividade de grãos em cultivares de arroz (Oryza sativa) pela interferência do capim-arroz (Echinochloa spp.). Planta Daninha, v. 25, n. 4, p. 697-707, 2007a.

GALON, L. et al. Níveis de dano econômico para decisão de controle de capim-arroz (Echinochloa spp.) em arroz irrigado (Oryza sativa). Planta Daninha, v. 25, n. 4, p. 709-718, $2007 \mathrm{~b}$. 
GALON, L. et al. Competição entre plantas de arroz e biótipos de capim-arroz (Echinochloa spp.) resistente e suscetível ao quinclorac. Planta Daninha, v. 27, n. 4, p. 701-709, 2009.

INSTITUTO RIO-GRANDENSE DO ARROZ - IRGA. Arroz irrigado no RS: - área, produção e rendimento Disponível em:_ $<\mathrm{http}: / /$ www.irga.rs.gov.br $>$ Acesso em: 05 out. 2009

LAMEGO, F. P. et al. Tolerância à interferência de plantas competidoras e habilidade de supressão por genótipos de soja - II respostas de variáveis de produtividade.

Planta Daninha, v. 22, n. 4, p. 491-498, 2004.

LINDQUIST, J. L. et al. Stability of corn (Zea mays)velvetleaf (Abutilon theophrasti) interference relationships. Weed Sci., v. 44, n. 2, p. 309-313, 1996.

LINDQUIST, J. L.; KROPFF, M. J. Application of an ecophysiological model for irrigated rice (Oryza sativa) Echinochloa competition. Weed Sci., v. 44, n. 1, p. 52-56, 1996.

MALUF, A. M. Interferência interespecífica entre Amaranthus hybridus L. e Amaranthus viridis L. Pesq. Agropec. Bras., v. 34, n. 5, p. 723-732, 1999.

MENEZES, V. G.; SILVA, P. R. F. Manejo de arroz vermelho através do tipo e arranjo de plantas em arroz irrigado.

Planta Daninha, v. 16, n. 1, p. 45-57, 1998.

PEDROSO, B. Densidade e espaçamento entre linhas para arroz (Oryza sativa L.) irrigado. Lav. arrozeira, v. 40, n. 370, p. 6-60, 1987.

PINTO, J.J.O. et al. Controle de capim-arroz (Echinochloa spp.) em função de métodos de manejo da cultura do arroz irrigado. Planta Daninha, v.26, n.4, p.767-777, 2008.
RIZZARDI, M. A.; FLECK, N. G.; AGOSTINETTO, D. Nível de dano econômico como critério para controle de picão-preto em soja. Planta Daninha, v. 21, n. 2, p. $273-282,2003$.

RIZZARDI, M. A. et al. Interferência de populações de Euphorbia heterophylla e Ipomoea ramosissima isoladas ou em misturas sobre a cultura da soja. Planta Daninha, v. 22, n. 1, p. 29-34, 2004.

RIEFFEL NETO, S. R. et al. Resposta de genótipos de arroz irrigado ao arranjo de plantas. Pesq. Agropec. Bras., v. 35, n. 12 , p. $2383-2390,2000$.

SAS INSTITUTE. Statistical Analysis System. User's guide version 6. 4.ed. Cary: 1989. 846 p.

STREIBIG, J. C. et al. Estimation of thresholds for weed control in Australian cereals. Weed Res., v. 29, n. 2 , p. 117-126, 1989.

SWINTON, S. M. et al. Estimation of crop yield loss due to interference by multiple weed species. Weed Sci., v. 42, n. 1, p. 103-109, 1994.

SOCIEDADE SUL-BRASILEIRA DE ARROZ IRRIGADO

- SOSBAI. Arroz irrigado: Recomendações técnicas da pesquisa para o Sul do Brasil. Santa Maria: Universidade Federal de Santa Maria, 2005. 159 p.

TIRONI, S. P. et al. Habilidade competitiva de plantas de arroz com biótipos de capim-arroz resistente ou suscetível ao quinclorac. Planta Daninha, v. 27, n. 2, p. 257-263, 2009

VENCILL, W. K. (Ed.). Herbicide handbook. 8.ed. Lawrence: Weed Science Society of America, 2002. 493 p.

VITTA, J. I.; FERNANDEZ QUINTANILLA, C. Canopy measurements as predictors of weed-crop competition. Weed Sci., v. 44, n. 3, p. 511-516, 1996. 